\title{
De Pointis y la representación textual DE LA EXPEDICIÓN A CARTAGENA EN 1697: TIPOLOGÍA DISCURSIVA, AMBIGÜEDAD Y PRAGMATISMO TRASCENDENTAL
}

\author{
Ricardo Borrero Londoño \\ Universidad de los Andes, Colombia \\ ricardoborrero373@hotmail.com
}

\section{Resumen}

Muchas de las discusiones en torno al "giro lingüístico" permanecen en el plano teórico, así que se aplicará la tipología discursiva a un ejemplo concreto: la representación textual de la toma de Cartagena en 1697. Se demuestra que el asedio osciló entre el corso, la piratería y la empresa cortesana, a causa de lo cual se originó una relación en que el tipo y el metatexto no tienen correspondencia, pues además de pender entre la oficialidad y la no oficialidad, fue estructurada como una epopeya o mito heroico. En suma, se da a entender que la ambigüedad del asedio encauzó una manifestación discursiva que se resiste a ser etiquetada, incluso al usar el sistema de clasificación más inclusivo y específico.

Palabras clave: tipología discursiva, representación textual, metatexto, lugar de producción, corso, piratería.

\section{Abstract}

Considering that most discussions regarding the "linguistic turn" have remained in the theoretical universe, the discourse typology will be put in practice by using the concrete example offered by the textual representation of the taking of Cartagena de Indias in 1697. It will be demonstrated that the capture oscillated between corsair, piracy and court company, which originated a relation hanging between an official and a non-official document. Thereafter, we will show that the latter was structured as an epic poem or heroic myth, so that the type and metatext don't seem to correspond. Finally, we will explain that the ambiguous character of the capture gave rise to a discourse manifestation which resists itself to be labeled, even using the most inclusive and specific classifying system.

Key words: Discourse typology, textual representation, metatext, place of production, corsair, piracy. 


\section{$\ldots$ Introduccion ${ }^{1}$}

Durante el reinado de los Habsburgo, Cartagena se convirtió en blanco frecuente de las hostilidades de algunos particulares codiciosos que, impulsados por los gobernantes de las principales potencias europeas, desafiaron el monopolio español sobre el Caribe. La ciudad fue dotada con una imponente infraestructura militar (Marco Dorta; Segovia) para resguardar las riquezas de los reiterados ataques. No obstante, el 6 de enero de 1697 salió de Brest una poderosa escuadra que consiguió ponerle sitio.

La expedición comandada por Jean Bernard Louis Desjeans (barón de Pointis) bordeó la costa española y se orientó a Santo Domingo, adonde llegó 55 días después. Allí se sumaron varios navíos tripulados por bucaneros, hombres voluntarios y esclavos negros. Una vez en la costa neogranadina, con alrededor de 25 embarcaciones artilladas y 5 millares de hombres, la expedición tomó el fuerte de San Luis y accedió a la bahía externa a través de Bocachica.

Los defensores de Cartagena optaron por replegarse hacia la ciudad y, por orden del gobernador (Matta), abandonaron uno a uno los fuertes de Santa Cruz de Castillo Grande, Manzanillo y San Sebastián del Pastelillo. La indefensión de la bahía interna facilitó la toma de La Popa y de San Lázaro — actual Castillo de San Felipe de Barajas—, así como la instalación de una batería provisional que tras destruir la puerta de la Media Luna, fue trasladada a las cercanías de la ciudad, cuya toma transcurrió luego de un

1 El presente artículo contó con la ayuda del programa de becas de investigación en Historia Colonial del ICANH y se basa en el trabajo de grado que presentó el autor para optar al título de historiador en la Pontificia Universidad Javeriana, Colombia. El autor agradece, además, a las siguientes instituciones y personas que colaboraron para la realización de este trabajo: Fesme, Fundación Terra Firme, Academia de Historia de Cartagena. Personas: Jaime Borja, Paula Ronderos, César Torres, Silvia Cogollos, Carolina de Wittich, Óscar Saldarriaga, Monika Therrien, Martín Andrade, Almirante Barona, Lourdes de Villamizar, Gonzalo Zúñiga, Roberto Arrázola J., Alfonso Cabrera y Moisés Álvarez. 
breve intercambio de disparos que desencadenó la apertura de un boquete en la muralla.

Un año después de lo sucedido, fue publicada en Ámsterdam La relation de l'expédition de Carthagène: faite par les François en 1697. A lo largo de este invaluable documento, monsieur de Pointis consignó lo acaecido desde que concibió la expedición hasta que regresó a Brest. En la primera mitad del siglo XX apareció la versión en español de Roberto Arrázola, quien se basó en la traducción inglesa que había realizado Oliver Payne, en 1740. Aunque el trabajo de Arrázola se limitó a la transcripción, traducción y compilación de documentos, fue de gran utilidad, y al cotejar su versión con el texto holandés, a pesar de algunas inconsistencias, mostró su fidelidad.

En 1886, Soledad Acosta de Samper escribió una adaptación literaria delo sucedido, que aunque se basa en fuentes fiables, recrea el asalto mediante hipérboles en las cifras y diálogos ficcionales. William Thomas Morgan parece haber sido la primera persona en realizar un estudio historiográfico sobre el asalto de Pointis a Cartagena. Su investigación, publicada en 1932 en The American Historical Review, ofrece un panorama completo del contexto histórico del asalto. Una década más tarde, Porto del Portillo publicó una versión breve y menos rigurosa en el Boletín Historial de Cartagena.

Así, hasta 1960, eran muy pocos los escritos sobre el tema. En aquel año apareció la segunda versión académicamente autorizada: Cartagena de Indias: puerto y plaza fuerte, que referencia importantes documentos y brinda un panorama general de lo acaecido. De hecho, intentos posteriores de Marchena Fernández, Román Bazurto y Cruz Apestegui reproducen, en mayor o menor medida, lo que en ella relata Marco Dorta.

Lucena Salmoral también trae a colación el asedio de monsieur de Pointis en uno de sus libros. Plantea que durante la toma de Cartagena los piratas fueron puestos al servicio de los intereses de Francia. Así mismo, afirma que este episodio fue el culmen de la agonía filibustera. En el Ensayo bibliográfico, acerca de la piratería americana, publicado en el número 12 de esta revista, Moreno Álvarez resume la versión de Lucena Salmoral sobre lo sucedido en Cartagena, en 1697. 
En 1979, Enrique de la Matta planteó, en un libro destinado exclusivamente al asalto de Pointis a Cartagena, que éste fue posible gracias a la cooperación del gobernador Diego de los Ríos y que a su vez fue uno de los acontecimientos más determinantes en el subsiguiente declive de la plaza e, incluso, de la monarquía española. Pese a servirse de fuentes no tenidas en cuenta y aún erigiéndose en el primer estudio detallado sobre el tema, el componente teórico parece ausente en este trabajo que, no obstante, ha servido como guía para los estudios posteriores sobre el asedio. Se destacan: la versión ilustrada que Gonzalo Zúniga presentó en su libro sobre San Luis de Bocachica y aquella que ofrece Eduardo Lemaitre en su Historia general de Cartagena. Por desgracia, la obra de Zuñiga no es del todo clara al indicar la procedencia de la información.

Cartagena de Indias en el siglo XVII (Meisel Roca y Calvo Stevenson) recoge las memorias del V Simposio sobre la Historia de la ciudad, en el cual se celebró una mesa redonda para discutir por qué cayó en 1697. Allí están consignadas las versiones más recientes. En líneas generales, éstas recogen una vez más la exposición de Matta, quien partió de la misma pregunta.

Volviendo al documento de Desjeans, cabe mencionar que aunque está lleno de meandros en que se plantean situaciones hipotéticas, no presenta partición explícita y goza de una escritura fluida. Abarca más o menos unas 50 páginas a lo largo de las cuales se recapitula el preámbulo de la salida, el trayecto entre Brest y Santo Domingo, lo acaecido en la isla antes de zarpar, el desembarco en las inmediaciones de Cartagena y la operación militar que condujo a su capitulación. Se relatan también el recaudo de bienes y dinero, la salida de las autoridades y, finalmente, el tortuoso viaje de regreso.

A similitud del común de los textos coloniales alusivos al "Nuevo Mundo", la Relatión de monsieur de Pointis fue erróneamente englobada bajo el calificativo de "crónica", como resultado de los procesos imprecisos de clasificación en que la prosa narrativa colonial fue homogeneizada por aludir a un mismo referente y haber sido escrita en una misma época.

Cabe anotar que este debate en torno a la catalogación documental recobró su vigencia cuando los seguidores de Wittgenstein explayaron los 
alcances de la preocupación por la forma y el discurso, al campo de la historiografía. Tras plantear que el lenguaje trasciende la función significante, han desviado la vista de los contenidos y han volcado el interés sobre la forma, mediante el reconocimiento del papel que cumple el lenguaje en la configuración de realidades.

Así, se propuso una nueva forma de clasificación, que parte de características extensibles a todo un tipo discursivo (Mignolo), pero no a los demás. Gracias a este procedimiento, el conjunto de textos antes englobados como "crónicas" hoy pueden distribuirse en varios grupos específicos. Los aspectos que se deben considerar son: el metatexto o modelo estructural (White, El contenido), el lugar de producción o agente de actividad (Certeau), la motivación o propósito y la acepción original del término con que se alude a cada tipo discursivo.

Por ejemplo, las relaciones oficiales de la Conquista y Colonización, acorde con la connotación que la expresión tenía, eran informes solicitados por la Corona, a causa de lo cual se organizaban a partir de un cuestionario. Generalmente no estaban a cargo de un letrado (Mignolo 70). En este orden de ideas, los documentos que cuentan con estas características deben catalogarse como relaciones oficiales y con base en este procedimiento, los textos antes englobados como "crónicas" hoy pueden etiquetarse como historias, cartas, diarios, etc.

Esta nueva heurística parecería apuntar a la resolución de un problema meramente nominal, pero al tomar en consideración su minucioso procedimiento, notaremos que esta afirmación es un argumento acrítico para soslayar o trivializar la rigurosa labor que debe anteceder el trabajo hermenéutico.

Ahora bien, haremos un esfuerzo por demostrar que la expedición a Cartagena en 1697 osciló entre el corso, la piratería y la oficialidad. Acto seguido, buscaremos poner en evidencia que su ambigüedad encauzó una relación estructurada como epopeya o mito heroico. Una manifestación discursiva de clasificación igualmente confusa, en que el tipo, el metatexto y el período de producción parecerían no tener correspondencia. 
Mediante el desarrollo de estas hipótesis, someteremos a prueba la utilidad práctica de la tipología discursiva. Usaremos la deconstrucción, concebida como un procedimiento de lectura y no como un método o sistema filosófico. Según el responsable de la acuñación del término, la deconstrucción parte de la "...necesidad de formular preguntas trascendentales para no quedar atrapado en un incompetente discurso empirista $y$, por lo tanto, para evitar el empirismo, el positivismo y el psicologismo ..." (Derrida 155). Es una estrategia de lectura minuciosa, prudente y propositiva, que consiste en desarticular una estructura, para poner en evidencia su constitución y sus contradicciones internas.

Por último, la representación fue de gran utilidad para comprender el texto, en cuanto éste "...muestra una ausencia, lo que supone una neta distinción entre lo que representa y lo que es representado...” (Chartier 57). Es decir, fue concebido como herramienta de un conocimiento indirecto que permite ver el asedio a través de una imagen narrada que lo suplanta y es capaz de traerlo a la memoria.

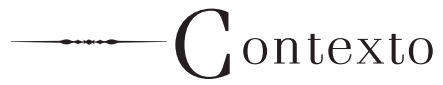

\section{AMbig ÜEDAD EN LO REPRESENTADO}

Con el siglo XVII, el centro de poder se desplazó del Mediterráneo a la región báltica, y el declive de la economía ibérica se hizo perceptible. La posición detentada por España se debatió entre Inglaterra y Francia. En 1686 se conformó la Liga de Augsburgo, con el fin expreso de frenar la expansión francesa. Tres años más tarde, con la adhesión de Inglaterra, la Liga cambió su nombre por el de Gran Alianza (Rubio).

En aquel contexto, la guardia francesa tuvo la oportunidad de demostrar lo beneficiosa que había sido la renovación impulsada por Le Tellier.Las victoriosas campañas en el Rosellón, Renania, Cataluña, entre otras, consolidaron la iniciativa modernizante de crear una ejército estatal que, poco a poco, sepultó al sistema de mesnadas que imperaba en el feudalismo. 
Los siglos XV y XVI habían traído grandes avances en materia de guerra. El creciente uso de la pólvora había impulsado el perfeccionamiento de la bombarda y la invención de la cureña, que además de facilitar el desplazamiento de la artillería, aumentó considerablemente la precisión de tiro. Estos adelantos jalonaron, a su vez, el desarrollo de la teoría de la fortificación.

En materia de milicia se implementaron las compañías reales de ordenanza, que consistían en agrupaciones de infantes o caballeros que recibían una paga y eran equipados mediante fondos provenientes de los impuestos; también se fundaron escuelas para la formación de oficiales. No obstante, la mayoría de los soldados siguieron siendo "... suministrados y equipados por las comunidades" y "se ejercitaban en la guerra sin abandonar el cultivo de los campos." (Voltaire 333).

\section{Jean Bernard Luis Desjeans,}

BARÓN DE POINTIS: UN ALMIRANTE

De la Marina Real lidera una empresa corsaria

Como en el siglo XVII los soldados profesionales seguían siendo pocos, la mayoría de los ejércitos navales estaban conformados por armadores investidos con patentes de corso (Moreno 375), pero éste no fue el caso de Jean Bernard Luis Desjeans, cuyos datos biográficos nunca sugieren que haya obtenido una. Por el contrario, indican que formó parte de la oficialidad durante toda su vida y que ocupó cargos de importancia en la Marina Real francesa; fue jefe de escuadrón, comisario general de la Artillería y almirante. Además, ostentó los títulos de barón y caballero (Michaud, "Jean Bernard").

Pese a su posición, Desjeans no mostró interés en ocultar que el monarca proporcionó el apoyo militar requerido para la toma de Cartagena. La contribución fue evidenciada desde el primer párrafo del documento, en el cual a su vez señaló que el plan había partido de su iniciativa y no de la del rey: "... había recibido de Su Majestad la aprobación del proyecto que yo tuve el honor de presentarle y también contaría con los hombres, buques, municiones, etcétera, que yo pensaba fueran necesarios llevar conmigo en dicha expedición" (cit. en Arrázola 23). 
Casi sobra aclarar que la generosidad del soberano no era gratuita. En efecto "Su Majestad había graciosamente concedido la décima parte del primer millón del botín y la tercera parte de los millones restantes a todos los hombres que tomaran parte en la expedición” (cit. en Arrázola 30). Es decir, él percibiría la mayoría de las riquezas.

El proyecto contó, así mismo, con el apoyo de burgueses y nobles, como monsieur de Pont-Chartrain, el conde de Maurepas y el tesorero general Vallone. De hecho, "Apenas nuestro designio se hizo público, comenzó a afluir el dinero a nuestras manos en forma inesperada. Todo el mundo en el país quería contribuir a la empresa." (cit. en Arrázola 23), comentaba orgulloso de Pointis.

Ahora bien, al tomar en consideración el carácter crediticio de las aportaciones, no tenemos por qué extrañarnos al ver que la acción fue literalmente concebida como una empresa: "Una compañía de capitalistas corrió con los gastos del armamento con la condición de tener participación de las ganancias." (Michaud, "Jean Bernard” 579).

Finalmente, el léxico del almirante no deja dudas en torno al marcado carácter financiero de la expedición. Entre las expresiones que así lo atestiguan se cuentan: "gestión, fondos suficientes, gastos, dinero, empresa, suma fijada, suma gastada, pérdida irremisible, más dinero, devolución de dinero, retiro del capital invertido, minuta de consejo, seguridad de inversión, bolsa, resultados monetarios, dinero anticipado y cálculo." (Arrázola 23-24).

Lo anterior lleva a concluir que si la toma de Cartagena se produjo en el marco de un conflicto entre Francia y España (Rubio), sería poco astuto interpretarla como un suceso de guerra. El hecho de que Luis XIV necesitara recursos para mantener su holgado tren de vida y el que adicionalmente buscara la abdicación del trono español en favor de uno de sus nietos (Zúñiga 74; Lucena 228) no eran razones suficientes para justificar la invasión de un dominio ultramarino.

Para cerrar, señalemos que si "El corso era así una actividad subvencionada por el mismo estado [... apoyada económicamente por burgueses e 
incluso por nobles ..." (Lucena 37), la toma de Cartagena se ciñó rígidamente a la descripción.

\section{Jean Baptiste Ducasse, gobernador de Santo Domingo: un CORSARIO ENCABEZA UnA ACCIÓN PIRÁtica} La figura que seguía en importancia a monsieur de Pointis era Jean Baptiste Ducasse, quien también ostentó cargos altos en la oficialidad francesa. Dehecho,cuandoseefectuóla expedición,ocupabala GobernacióndeSanto Domingo (Arrázola 27; Michaud, "Jean Baptiste" 97 -99; Lucena 225).

Según cuenta Esquemeling, una de las principales ocupaciones de los franceses que habitaban en aquella isla era la piratería (110). Esta situación era conocida por el gobernador, quien en vez de tomar cartas en el asunto, parecía propiciarlo. En efecto, Michaud indica que lo que hizo posible el ingreso de Ducasse al cuerpo de marina fue el ataque de una flota holandesa, pero al señalarlo parece olvidar que cuando lideró aquella arremetida, se hallaba "... provisto de patente de Corso ..." (Matta 30). Para sumarse a ello el barón comenta que "...él decía que tomaría parte en la expedición como un soldado privado” (cit. en Arrázola 28), lo cual despeja la incertidumbre residual en torno a su posición.

\section{Los bucaneros y Filibusteros de Santo Domingo} AL SERVICIO DE LAS ASPIRACIONES REALES Con el Tratado de Turín, la actitud beligerante de la corona francesa dio un giro trascendental: "Se firmó la paz con Saboya y se creía muy probable que pronto se firmaría una paz general." (Arrázola 23). Esta situación despertó la desconfianza de ciertos inversionistas, que prefirieron retirar sus aportes, y así disminuyó la fuerza con que debía contar la expedición. No obstante, la carencia pudo ser subsanada con la participación de un grupo de filibusteros ${ }^{2}$ reclutados por Ducasse, quien afirmó:

2 Aunque la edición de 1698 emplea el vocablo flibustiers para referirse a quienes acompañaron a Desjeans en la expedición, Payne y Arrazola utilizan las palabras buccaniers y bucaneros. Por 
“... había tenido una gran suerte en encontrar aquellos piratas ...” (cit. en Arrázola 28).

La utilización de la palabra piratas implica reconocer que "... tales hombres no eran sujetos ni vasallos de sus Majestades ...” (Esquemeling 121), en tanto que “. .. un pirata, a secas, no tenía filiaciones de ningún tipo con una nación o soberano y se movía con el fin exclusivo de obtener el máximo posible de ganancias en sus operaciones" (Moreno 381).

Pese a lo anterior, de Pointis explica que si aquellos hombres habían operado de manera independiente, luego fueron sometidos a la jurisdicción de Santo Domingo y que "... quienes los consideran súbditos del Rey, las más de las veces, son aquellos que los necesitan y por consiguiente no tienen ningún inconveniente en hacerles la corte." (cit. en Arrázola 29). Con el claro propósito de incriminar a Ducasse, interpola a lo citado que "Las ventajas que sus servicios pueden traer a los gobernadores los libra de la persecución de la ley a que son deudores ... y que "Como la gobernación de Santo Domingo ha sido muy enriquecida por ellos, se les perdonan con indulgencia las barrabasadas de que hacen víctima a los españoles..." (cit. en Arrázola 29).

Irónicamente, Desjeans se “... encontraba en caso de apremio y realmente necesitaba de aquellos hombres ...” (Arrázola 30) para llevar a feliz término su lucrativa empresa antiespañola, con lo cual demuestra que su actitud frente a la piratería no diverge en absoluto del utilitarismo que critica en los demás. Ahora bien, al tomar en consideración que los bucaneros reclutados en Santo Domingo sumaban un total de 600, cabría sospechar que hubieran llegado de las islas vecinas en respuesta a un llamado, pues en aquella época quedaban pocos en La Española (Esquemeling 110), pero: 
Cuando se decide hacer una "expedición", se envían correos a todas las islas señalando una fecha y un lugar de reunión. Allí acuden los capitanes "solitarios" y se convoca un consejo de guerra que fija todos los detalles del asalto. Cuando se llega a un acuerdo empieza a funcionar la disciplina. Cada uno tiene su puesto y su lugar a desempeñar; y antes de levar anclas el botín ya ha sido teóricamente dividido... (Gall y Gall 149)

Con base en la dilación que dieron los bucaneros al embarque, cabría sospechar que aguardaban a algunos colegas; pero, más allá de las conjeturas, existen certezas que hablan de una convergencia entre la empresa y la descripción general de expedición filibustera que ofrecen los hermanos Gall. A saber, cuando "... quedó todo listo para zarpar [... ] hubimos de dilucidar un punto muy importante: los piratas querían estar seguros de cuánto recibirían de botín y, asimismo, querían una garantía de que su parte les sería entregada." (cit. en Arrázola 29). Con ello se produjo la repartición hipotética de la presa que inmediatamente fue consignada por escrito.

En el contrato que firmaban los bucaneros antes de partir, “... especifican cuánto debe tener el capitán [ ... ] después estipulan las recompensas, y premios de los que serán heridos o mutilados de algún miembro” (Esquemeling 126). Es decir, que al ordenar “... que todos los piratas que hubieran sido heridos en acción, recibieran premios en efectivo...” y que los capitanes fueran gratificados (Arrázola 64), de Pointis se mostró respetuoso ante el derecho consuetudinario del filibusterismo. Sólo hacía falta establecer la jerarquía y no tardó en hacerlo, al señalar que en él “... encontrarían un jefe que les daría órdenes, pero en ningún caso un compañero de fortuna ...” (cit. en Arrázola 30).

Lo anterior nos obliga a disentir de las palabras de Lucena, cuando afirma: "El ataque distó mucho de ser una empresa filibustera, ya que lo dirigió Pointis dentro de las normas más estrictas de la armada francesa” (Lucena 228). Así, aunque la toma de Cartagena se ajusta a la caracterización de empresa corsaria, en este punto también parece encuadrar en la descripción de expedición pirata que ofrecen los Gall.

Agregaremos que las incursiones de los piratas en territorios custodiados por las metrópolis fueron escasas y que se caracterizaron por su 
fugacidad y que aun cuando eran más dados al abordaje, en ciertas oportunidades se permitían el desembarco y el asedio de ciudades costeras, pero al cabo de pocos días, cuando éstas habían sido completamente saqueadas, las abandonaban y sus habitantes huían mientras los bucaneros emprendían la retirada.

Al tener en cuenta que durante la toma de Cartagena se procedió de esta manera y que, como cuenta Zúñiga (comunicación personal), los fondos recaudados con el expolio fueron empleados en la remodelación del Palacio de Versalles, creemos que este episodio fue una de las oportunidades en que "... los filibusteros fueron hábilmente aprovechados y domesticados por Inglaterra, Francia y los Países Bajos ..." (Moreno 376).

Conviene señalar que no somos los primeros en incluir este acontecimiento en el conjunto de acciones corso-piráticas que tuvieron lugar en el Caribe. En efecto, ha sido incorporado en la mayoría de compendios sobre el tema (Acosta de Samper; Román; Cruz; Haring; Lucena; Moreno); sin embargo, recordar el carácter de la empresa esclarece su lugar y proporciona información muy valiosa al primer componente de la fórmula contexto-texto-metatexto.

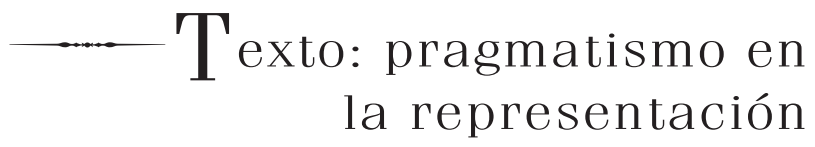

Acorde con lo anterior, la empresa procede de un lugar real-corso-pirático, lo cual acarrea nuevas dificultades a la hora de identificar la intención con que fue representada textualmente. Partir de una conclusión tan vaga tampoco hace fácil determinar a qué tipo discursivo pertenece la representación; sin embargo, tener por cierto que el propósito de Desjeans al venir a América fue poner sitio a Cartagena ayuda a esbozar las respuestas a estos interrogantes.

Dado el cariz empresarial de la expedición, el documento pudo haber servido para informar a los inversionistas. Esta idea converge con la línea argumentativa que invita a pensar que, acorde con su título, el texto 
es una relation. No obstante, sus párrafos carecen de numeración y están perfectamente interconectados, así que su estructura va en contravía del formato que seguía este tipo discursivo, usualmente regido por cuestionarios y dirigido a alguien que ocupaba un cargo alto.

Así mismo, en discordancia con la prosa de un hombre poco docto, el escrito capta la atención del lector desde la primera frase, con la cual crea un clima confidente que entremezcla nostalgia e indignación. Aunque cabría pensarlo, la extensión del documento hace desconfiar de que haya sido concebido como carta. Además, éste era un tipo infrecuente durante el siglo XVII y los textos “... narrados a lo largo del recorrido, no suelen tener introducciones en las que se consigne un destinatario explícito, ni tampoco aparece la figura de un interlocutor a lo largo del texto” (López 172).

Por esta razón, insistir en que el documento es una carta o una relación, obligaría a reconocer la existencia de un destinatario tácito, pero el nombre del receptor no es mencionado jamás, a diferencia de lo que sucede cuando se escribe, porque lo "...mandó azer el muy ilustre señor don Lope de Orosco..." (cit. en Tovar 309) o cualquier otra persona. Tampoco se menciona su posición, como hacían las gentes para dirigirse "Al Xristianisimo y muy alto y muy poderoso príncipe Rey Nuestro Señor” (Núñez de Balboa, cit. en Tovar 79). De hecho, no hay ni siquiera una referencia indefinida, como la que utilizan los autores que sencillamente hablan a "...el lector..." (Fernández 56).

De este modo, nos encontramos frente a un relato de viaje “... estructurado a partir de la voz de un narrador viajero...” (López 172) que usa la primera persona, y dada su proximidad al pasado que representa, desconoce su desenvolvimiento definitivo. Esta perspectiva de narrador-protagonista recibe el nombre de focalización interna directa e invita a pensar que el texto fue escrito sobre la marcha. No obstante, recordar que la escritura está supeditada a la función regente del autor lleva a concluir que la utilización de múltiples tonos refleja la destreza dramática del escritor y no la simultaneidad entre el acontecer y su recreación literaria. En otras palabras, quien posee la historia, posee el discurso y, por ende, utiliza el pretérito. 
Si bien es cierto que las actividades bélicas acaparaban buena parte del tiempo de Desjeans, el uso frecuente de fechas le permite crear una secuencia temporal que parecería derivar de un cronograma estricto de escritura. Sin embargo, la engañosa rigidez de su cronología se diluye en referencias imprecisas como: “... cincuenticinco días después ...” (cit. en Arrázola 26).

Aunque son pocas, las referencias como ésta dejan entrever el lapso que podía mediar entre dos sesiones de escritura o entre dos acontecimientos dignos de mención. De igual manera, descubren la intención que tenía el almirante de emular la realidad del tiempo transcurrido, mediante el hilo conductor de la narrativa (Ricoeur). Por eso el escrito cuenta con un inicio, un nudo y un desenlace. Concatena eventos viejos con eventos nuevos para dar continuidad a un ejercicio literario integrado por sesiones dispersas en el espacio y en el tiempo. Es decir, trasciende la serialidad de la protonarrativa conformada por los textos que se inician cuando el autor comienza a registrar los hechos y concluyen en el momento en el cual éste se detiene (Ricoeur; White, El contenido). En síntesis, dista de ser “... una lista organizada sobre las fechas de los acontecimientos que se desean conservar en la memoria." (Mignolo 75) y por eso ni es una crónica, ni tampoco un diario.

Ahora bien, para afirmar que el discurso es de carácter historiográfico, podríamos decir que el almirante escribió un "... informe de los tiempos de los cuales, por su trayectoria vital, es contemporáneo” (Mignolo 75), pues ésta fue la definición que se mantuvo entre los tratadistas historiográficos hasta el siglo XVII. No obstante, el gran hombre cuenta sus hazañas sin la mediación de un personaje de letras, lo cual aleja el documento de este tipo discursivo. Es de recordarse que el sujeto historiado no puede ser el sujeto historiante, como en el caso de la autobiografía.

Por otra parte, las preocupaciones de orden moral y natural que se entrevén a lo largo del documento eran subsidiarias de unos fines prácticos inmediatos y estaban lejos de ser las principales motivaciones para escribir. Al ocuparnos de los piratas, aclaramos que si al barón le “... resultaba horriblemente desagradable el trato con ellos ...” (Arrázola 29), el imperativo 
que le exhortaba a abstenerse de esta relación, estaba subordinado al potencial de su empresa. Veamos ahora cómo los intereses de orden natural también subyacen a unos objetivos prácticos:

Quiero hacer notar que allí en la costa de Cartagena, los bosques ofrecen el raro espectáculo de llegar hasta el mar y por consiguiente son ellos un magnífico sitio para la defensa. Los enemigos podrían esconderse allí y esto me obligaba a ser muy precavido. (Cit. en Arrázola 40)

Si bien es cierto que los textos intitulados Historia general y natural de las Indias también fueron escritos atendiendo a la utilidad que las plantas y animales pudieran tener, en general, perseguían las propiedades alimenticias o medicinales, es decir, evidenciaban las características y cualidades de los elementos, con objetivos menos inmediatos que los de Desjeans, quien describía la naturaleza en función de las posibilidades que proporcionaba a una acción militar determinada, enmarcada en su propia campaña.

Aunque sus datos biográficos no lo explicitan, por su elevada posición cabría esperar que el barón hubiera sido versado en retórica. No obstante, las pretensiones de verdad y persuasión brillan por su ausencia. El almirante no acude a otros testigos, ni hace referencia explícita a las autoridades clásicas o a Dios. En efecto, no menciona sus fuentes, ni expone la intención testimonial de presentarse como testigo “... por averlo visto, e ser publico y notorio." ([Garçia] de la Vega). En suma, se desconoce la intención de Fernández de Oviedo, que al poner de facto sus motivaciones para escribir historia, niega la retórica mediante una estrategia retórica, e insta al lector a creer que:

[... no lee fábula, ni cosas aquí acumuladas por pasar tiempo en hablar con ornada oración o estilo, como algunos hacen, porque de todo esto carecen estos tractados, e solamente escriptos para notificar verdades y secretos de la Natura, llana e verdaderamente escriptos, a gloria e loor de Dios. (Fernández 56)

Por tales razones, la representación no podría considerarse historiográfica, ya que pese a encajar en la definición de historia que se daba en la época, no cumple con los parámetros y cánones de escritura que maneja este saber desde el siglo V a. C., cuando Herodoto y Tucídides ya habían reconocido la importancia de las pruebas (Hartog 386). 
Como hemos agotado los principales tipos de la Colonia, debemos reconsiderar aquella propuesta según la cual el documento estaba dirigido a los que aguardaban en casa ansiosos por conocer el destino de " ... la enorme suma gastada ...” (cit. en Arrázola 23). Allí encajaría el empeño que pone el barón en adular al Rey Sol, que fue el inversionista mayoritario. Es decir, “... con la esperanza de que su texto más tarde tuviese recepción y acogida dentro de los círculos del poder, para a través de ellos conseguir las recompensas o canonjías que se solían brindar a los que participaban en las empresas de la conquista." (López 72). De Pointis afirma que su mayor anhelo es conceder “.... honor, gloria y provecho a la Corona.” (cit. en Arrázola 69).

En síntesis, el texto “... no se inscribe en ningún modelo institucional, sino que es producto de las circunstancias ..." (Mignolo 101) y, a diferencia de los observadores “... compelidos por la necesidad de contar lo que sus propios ojos vieron ...”, monsieur de Pointis se hallaba en la obligación de “... rescatar los hechos acaecidos ..." (Las Casas, cit. en Mignolo 77) por ser el directamente “... responsable del honor de las armas de Su Majestad ...” (cit. en Arrázola 59).

Así pues, el almirante “... escribe sus experiencias, relata, hace relación de hechos que le parecen dignos de memoria” (Mignolo 101) y, por ende, el documento es una relación, que cumple con la función de informar a los interesados en la empresa mientras convierte a su protagonista en un héroe homérico y le permite “... servir y lisonjear a los príncipes ..." (Las Casas, cit. en Mignolo 77).

\section{-... Metatexto: trascendencia y heroización}

Hasta aquí hemos demostrado que el documento es una relación y que, por ende, está destinada a informar a los interesados en la empresa, así como a halagar al monarca. En adelante, haremos notar que el relato no sigue el patrón habitual de los textos que pertenecen a este tipo, pues al graficar su metatexto obtendríamos una onda cuya frecuencia inicia con picos 
bajos que se van haciendo cada vez más altos, hasta llegar a un punto en que comienzan a declinar, para desaparecer finalmente.

El trazado ascendente hacia cada uno de estos picos representa una barrera que se interpone en el camino que todo héroe debe seguir. Consecuentemente, los tramos descendentes simbolizan los momentos de distensión en que el héroe recibe ayudas que le sirven para salir de apuros. El clímax del relato está situado en la cúspide más elevada de la gráfica y representa la gran meta. No obstante, el destino no se consuma al trascender el pico mayor, pues restan algunos inconvenientes que también deben superarse.

En la relación, tras las pequeñas colinas a que dan lugar las vicisitudes de la salida y las sorpresas negativas en la isla de Santo Domingo, la tentación de olvidar Cartagena y tomar Veracruz dibuja un pico elevado. Allí, Ducasse hace las veces de Calipso y, por ende, al rechazar su propuesta (Arrázola 32), el barón se encamina nuevamente y se orienta al descenso. Una nueva cumbre asoma cuando tiene que enfrentar los fallecimientos del vizconde de Cotlogon y el caballero de Pointis (Arrázola 57). Aunque su gran amigo Levy pervive, estas pérdidas son casi comparables con las muertes de Enkidu, Prítoo y Patroclo, en los relatos de Gilgamesh, Teseo y Aquiles.

Finalmente, así como Perseo disfrutó de la ayuda de Atenea, Desjeans contó con el apoyo de una Corte que le brindó “... su magnífico socorro..." (Arrázola 24). De igual forma, si para matar a la Gorgona Medusa, al primero se le concedieron unas sandalias con alas y un casco que lo hacía invisible; el segundo obtuvo del rey todo lo necesario para tomar Cartagena. Sin embargo, al igual que a Ulises le correspondió volver con Penélope y deshacerse de sus pretendientes para poder ser venerado, el barón tuvo que enfrentar la escuadra de Neville y regresar a salvo (Arrázola 71-72), antes de convertirse en héroe.

En este orden de ideas, la manera como está estructurada la relación remite a la época clásica, una de cuyas figuras más insignes dio vida al rey de Ítaca a lo largo de la Ilíada y la Odisea, que si bien son las epopeyas más 
famosas, distan de ser las únicas obras pertenecientes al género. En efecto, éste parece haber sido muy popular hasta bien entrado el siglo XVI, cuando comenzó a perder vigencia ante el empuje de la novela moderna:

En la Edad Media el espíritu caballeresco-feudal, animado por el impulso de las primeras nacionalidades, creó la epopeya medieval, que recibe el nombre más común de poema épico o cantar de gesta. Generalmente estas gestas o hazañas eran referidas a un individuo en quien se depositaban las virtudes heroicas de un pueblo o de una raza. (Berrío y Huerta 171-72)

Poco más tarde, cuando un sinnúmero de aventureros osaron cruzar la mar que se erigía como frontera entre la tierra conocida y la porción inexplorada del orbe, la epopeya recobró su forma clásica (Therrien). De la mano con el "descubrimiento", los caballeros y sus monturas se convirtieron en imágenes de un pasado oscuro, para abrir paso al Renacimiento, junto al cual advino el Humanismo.

Esta corriente tardó varios años en permear el suelo francés. No obstante, comenzó a echar raíces con la fundación del Colegio de Lectores Reales, en 1530. La institución impartió enseñanza de las lenguas clásicas y se convirtió en el epicentro de difusión humanista. Posteriormente, dio origen al Colegio de Francia, donde se formaron varios de los intelectuales de la corte.

Algunos años antes de que monsieur de Pointis emprendiera su viaje, Racine y Boileau fueron nombrados historiógrafos del Rey Sol y miembros de la Academia Francesa. Así fue contagiada la corte del clasicismo que se hallaba en pleno auge cuando Desjeans escribió su relación. En el seno de este movimiento cobró gran importancia la epopeya o mito heroico, ya que desde el mundo antiguo había sentado las bases para el retorno del individuo y la valoración de lo humano, que sirvieron a la cimentación del ideal renacentista, que pregonaban los mencionados intelectuales.

Ahora bien, aunque los datos acerca de la formación intelectual del almirante son prácticamente nulos, la génesis de su pensamiento es indisociable de aquella época de admiración por las artes grecolatinas, y dada su extracción social, es probable que haya entrado en contacto con la academia 
cortesana y, en particula,r con el Arte poética que escribió Boileau algunos años antes de su nombramiento como historiógrafo de Luis XIV. Este breve manual, inspirado en Aristóteles y Horacio, esbozaba las normas literarias que debían seguir los escritores. Adicionalmente, estaba redactado en un leguaje sencillo, que ponía la doctrina escritural al alcance de cualquier persona medianamente culta (González).

Aunque parezca curioso, durante la Conquista y la Colonización buena parte de los escritores estuvieron fuertemente influenciados por las autoridades clásicas. Así lo demuestran los estudios acerca de fray Pedro de Aguado (Borja), el Inca Garcilaso de la Vega (Hampe, "El renacimiento") y la literatura del virreinato peruano, en general (Hampe, La tradición; MacCormack).

En este orden de ideas, resulta un poco menos extraño que en pleno siglo XVII un almirante de la marina francesa haya escrito una relación que "... no se apega a la seca narración de los hechos acaecidos sino que se articula mediante estructuras 'migrantes' que provienen de distintos tipos y formaciones discursivas ...” (Mignolo 101). La atmósfera intelectual hizo que Hesíodo, Homero y Virgilio se erigieran en fuentes de inspiración obligadas para la relación de Desjeans, quien se representó como un marinero de la antigüedad, que mediante su osadía buscaba sumarse a la trina de Teseo, Odiseo y Jasón.

Finalmente "... el héroe, héros, es el que ha alcanzado la madurez, el que realiza el máximo de lo asignado a la condición humana..." (García Gual 170). Es un personaje “... real o imaginario, que evoca las actitudes y comportamientos apropiados ...” (Klapp 135), así que además del asedio a "... la más famosa ciudad de las Indias. Ella, la tan bien conocida en Europa, la de las fortificaciones amuralladas ...” (Arrázola 33), la Relation de l'expédition de Carthagène contribuyó ampliamente en la heroización del barón de Pointis. 


\section{Conclusiones}

En resumen, la toma de Cartagena en 1697 fue una empresa de carácter híbrido, que originó una relación cuya motivación pragmática consistía en halagar e informar al Olimpo de los inversionistas de aquello que sucedía. No obstante, un metatexto extrapolado de la antigüedad clásica confirió al documento la finalidad trascendental de heroizar a su protagonista, por ser un personaje ejemplar para la Francia de Luis XIV.

Como en buena parte de las epopeyas o mitos heroicos, el periplo y la batalla son los escenarios predilectos en que el héroe se desempeña. Allí hacen presencia los amigos, las malas compañías, las tentaciones y los avatares del clima que en algunas oportunidades parecerían ser más fuertes que aquel héroe, quien pese a las innumerables adversidades que enfrenta desde el momento en el cual sale de casa, consigue el anhelado triunfo.

El paradigma seleccionado es de aparición relativamente reciente, y desde su introducción en los países de habla hispana, hace algo menos de dos décadas, ha sido negativamente estereotipado. Contra lo que muchos piensan, la realización de un estudio en torno a la forma no necesariamente implica rechazo hacia los trabajos que se ocupan del contenido. Es sencillamente una propuesta distinta de aproximación a los textos que, producto del desconocimiento, ha encontrado pocos adeptos entre los historiadores colombianos, quienes con contadas excepciones se han mostrado renuentes a la aceptación de sus aportes.

Así, este ejercicio se suma a los esfuerzos precedentes por demostrar que en el seno de esta corriente no hay más que una preocupación legítima por la génesis del pensamiento a partir del lenguaje. ¿Acaso no hace ésta parte de la historia? Es cierto que lo esbozado por White en Metahistoria habría cobrado aún mayor utilidad al ser integrado con el estudio de lo acaecido pues, además de las facilidades que el análisis discursivo proporciona al trabajo hermenéutico, éste permite una comprensión de la historia y sobre todo de la historiografía, más tendiente al holismo. No obstante, 
una aproximación meramente "formalista" no necesariamente relativiza el valor cognitivo de las labores historiográficas y, de ser así, hace falta darse a la tarea de demostrarlo.

\section{Bibliografía}

Acosta de Samper, Soledad. Los piratas en Cartagena. Bogotá: Ministerio de Educación, 1946. Impreso.

Arrázola Caicedo, Roberto. Historial de Cartagena. Cartagena: Casanalpe, 1955. Impreso.

Berrío García, Antonio y Javier Huerta Calvo. Los géneros literarios: sistema e historia. Madrid: Cátedra, 1999. Impreso.

Borja, Jaime. Los indios medievales de fray Pedro de Aguado. Bogotá: Ceja, 2002. Impreso.

Certeau, Michel de. La escritura de la historia. México: Universidad Iberoamericana, 1993. Impreso.

Cruz Apéstegui. Los ladrones del mar. Piratas en el Caribe: corsarios, flibusteros y bucaneros 1943-1700. Madrid: Lunwerg, 2000. Impreso.

Chartier, Roger. El mundo como representación. Barcelona: Gedisa, 1992. Impreso.

Derrida, Jaques. "Notas sobre deconstrucción y pragmatismo". Deconstrucción y pragmatismo. Comp. Chantal Mouffe. Buenos Aires: Paidós, 1998. 151-70. Impreso.

Desjeans, Jean Bernard Louis. Relation de l'expedition de Carthagene: faite par les francoisen 1697. Ámsterdam: Héritiers d’Antoine Schelte, 1698. Impreso.

Esquemeling, Alexander Oliver. Piratas de la América y la luz de la defensa de las costas de Indias Occidentales. La Habana: Comisión Nacional Cubana de la Unesco, 1963. Impreso.

Fernández de Oviedo, Gonzalo. Historia general y natural de las Indias. Madrid: Biblioteca de Autores Españoles, 1959. Impreso.

Gall, Jacques y François Gall. El flibusterismo. México: FCE, 1957. Impreso.

García Gual, Carlos. Introducción a la mitología griega. Madrid: Alianza, 1992. Impreso.

[Garçia] de la Vega, Xristoval. "Proceso de Cristóbal de Vega maestre y Capitán Juan de Uribe Nao Espíritu Santo" [1584]. Transcrito por Ricardo Borrero en Base de datos para la historia colonial y el patrimonio cultural sumergido colombiano: s. XVI al XVIII. Bogotá: Icanh, 2007. Impreso. 
González Pérez, Aníbal. Poéticas: Aristóteles, Horacio, Boileau. Madrid: 1984. Impreso.

Haring, Clarence Henry. Los bucaneros de las Indias occidentales en el siglo XVII. Caracas: Academia Nacional de la Historia, 1939. Impreso.

Hartog, François. "The Invention of History: The Pre-History of a Concept from Homer to Herodotus". History and Theory, 39.3 (2000): 384-95. Impreso.

Hampe Martínez, Teodoro. "El renacimiento del Inca Garcilaso revisitado: los clásicos greco-latinos en su biblioteca y en su obra”. Histórica, 18.1 (1994): 69-94. Impreso.

Hampe Martínez, Teodoro, comp. La tradición clásica en el Perú virreinal. Lima: Universidad Nacional Mayor de San Marcos, 1999. Impreso.

Klapp, Orrin E. "The Creation of Popular Heroes". The American Journal of Sociology, 54.2 (1948): 135-41. Impreso.

Lemaitre, Eduardo. “Toma y saqueo de Cartagena por el barón de Pointis". Historia General de Cartagena. Bogotá: Banco de la República, 1983. Impreso.

López de Mariscal, Blanca. Relatos y relaciones de viaje al Nuevo Mundo en el siglo XVI. Madrid: Polifemo-Tecnológico de Monterrey, 2004. Impreso.

Lucena Salmoral, Manuel. Piratas, bucaneros, flibusteros y corsarios en América: perros, mendigos y otros malditos del mar. Madrid: Mapfre 1492, 1992. Impreso.

MacCormack, Sabine. On the Wings of Time: Rome, the Incas, Spain, and Perú. Princeton: Princeton University Press, 2007. Impreso.

Marchena Fernández, Juan. La institución militar en Cartagena de Indias en siglo XVII. Sevilla: Escuela de Estudios Hispano-Americanos, 1982. Impreso.

Marco Dorta, Enrique. Cartagena de Indias: puerto y plaza fuerte. Bogotá: Fondo Cultural Cafetero, 1988. Impreso.

Matta Rodríguez, Enrique de la. El asalto de Pointis a Cartagena de Indias. Sevilla: Escuela de Estudios Hispano-Americanos, 1979. Impreso.

Meissel Roca, Adolfo y Haroldo Calvo Stevenson. Cartagena de Indias en el siglo XVII. Cartagena: Banco de la República, 2007. Impreso.

Michaud, M. M. “Jean Bernard Desjeans: Barón de Pointis". Biographie universelle ancienne et moderne. V. 5. París: Louis Vives, 1880. 579-580. Impreso.

---. "Jean Babtiste Ducasse". Biographie universelle ancienne et moderne. V. 5. París: Louis Vives, 1880. 97-99. Impreso.

Mignolo, Walter. “Cartas, crónicas y relaciones". Historia de la Literatura Hispanoamericana. V. 1. Coord. Iñigo Madrigal. Madrid: Cátedra, 1998. 57-117. Impreso. 
Moreno Álvarez, Leonardo Guillermo. "La piratería americana y su incidencia en el Nuevo Reino de Granada, siglos XVI-XVII: un ensayo bibliográfico". Fronteras de la Historia, 12 (2007): 373-404. Impreso.

Morgan, William Thomas. "The Expedition of Baron de Pointis against Cartagena”. The American Historical Review, 37.2 (January, 1932): 237-254. Impreso.

Porto del Portillo, Raúl. "Asedio de Cartagena por el barón de Pointis". Boletín Historial, 9.8 (1945). Impreso.

Ricoeur, Paul. Tiempo y narración. México: Siglo Veintiuno, 1998. Impreso.

Román Bazurto, Enrique. "El Caribe teatro de codicia". Historia de las fuerzas militares de Colombia. T.2. Bogotá: Planeta, 1993. Impreso.

Rubio Mañé, Jorge Ignacio. El virreinato III: expansión y defensa. México: FCE, 1983. Impreso.

Segovia Salas, Rodolfo. Las fortificaciones de Cartagena de Indias: estrategia e historia. Bogotá: Carlos Valencia, 1982. Impreso.

Therrien, Monika. "Leyendas bajo el agua: patrimonio sumergido y arqueología subacuática”. Historias sumergidas: hacia el estudio y protección del patrimonio cultural subacuático. Bogotá: Universidad Externado de Colombia, 2006. Impreso.

Tovar, Hermes. Relaciones y visitas de los Andes: s. XVI. 4 t. Bogotá: Instituto de Cultura Hispánica-Colcultura, 1992-1995. Impreso.

Voltaire. El siglo de Luis XIV. México: FCE, 1996. Impreso.

White, Hayden. Elcontenido de laforma: narrativa, discurso y representación histórica. Barcelona: Paidós, 1992.

---. Metahistoria. México: Fondo de Cultura Económica, 1997.

Zúñiga Ángel, Gonzalo. Un gigante olvidado. Cartagena: Punto Centro-Forum, 1996. Impreso.

Fecha de recepción: 5 de mayo de 2009.

Fecha de aprobación: 6 de julio de 2009. 